\title{
Management of Old Neck Femur Fracture through Valgus Osteotomy and Pin Fixation
}

\author{
L Rathod C. ${ }^{1}$, Chauhan P. ${ }^{2 *}$
}

DOI: https://doi.org/10.17511/ijoso.2020.i05.05

\footnotetext{
${ }^{1}$ Chetan L Rathod, Associate Professor, Department of Orthopedics, Sri Muthukumaran Medical College, Chennai, Tamil Nadu, India.

2* Prakash Chauhan, Associate Professor, Department of Orthopedics, Sri Muthukumaran Medical College, Chennai, Tamil Nadu, India.
}

Introduction: Valgus intertrochanteric osteotomy alters the biomechanical environment of the fracture site and restores limb length. Very few reports have dealt with the results of this procedure internally fixed with a dynamic hip screw and double angle barrel plate. Hence, the prospective study was performed at the institution level for the evaluation of results of valgus osteotomy and fixation of the femur neck fracture in young patients. Material and Methods: A total of 32 patients were included in the study. There were 24 males and 8 females in the study. Before osteotomy, the average neck-shaft angle was $101^{\circ}\left(80-120^{\circ}\right)$, with an average limb shortening of $2.3 \mathrm{~cm}$ (1.0$3.2 \mathrm{~cm}$ ). The greater trochanter was up riding in fourteen cases and needed skeletal traction before surgery. None of these had evidence of vascular necrosis on plain radiograph or MRI. The fractures were treated with a dynamic hip screw and double angle barrel plate. The patients had a minimum follow-up of 14 months and a maximum of 42 months. Results: In a total of 28 patients the excellent results were obtained, however in 4 patients the poor result was due to cut - out of implants. None of the patients were lost on follow up, the fracture went on to achieve the satisfactory union after the minimum of 14 weeks follows up. The average preoperative neck-shaft angle of $101^{\circ}$ (range $80-$ $120^{\circ}$ ) increased to $134^{\circ}$ (range $120-145^{\circ}$ ) after surgery. The average limb length discrepancy postoperatively was $2.3 \mathrm{~cm}$. Conclusion: From the study, it was concluded that valgus osteotomy and fixation with dynamic hip screw and $120^{\circ}$ double angle barrel plate has a high success rate in young patients with neglected and ununited intracapsular fracture neck of the femur as far as the union of fracture is concerned.

Keywords: Femur fracture, Valgus osteotomy, Non-union, Barrel plate

\section{Corresponding Author}

Prakash Chauhan, Associate Professor, Department of Orthopedics, Sri Muthukumaran Medical College, Chennai, Tamil Nadu, India.

Email: drpcortho@hotmail.com
How to Cite this Article

To Browse

Rathod CL, Chauhan P. Management of Old Neck Femur Fracture through Valgus Osteotomy and Pin Fixation. Surgical Rev Int J Surg Trauma Orthoped. 2020;6(5):316-320.

Available From

https://surgical.medresearch.in/index.php/ijoso/artic le/view/208

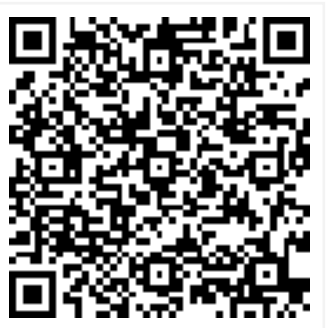

Manuscript Received 2020-09-29

Conflict of Interest No
Review Round 1 2020-10-09 $\mathrm{Nil}$
Funding

$\begin{gathered}\text { Review Round } 2 \\ 2020-10-16\end{gathered}$
Ethical Approval
Yes

Review Round 2

Yes
Review Round 3

Plagiarism X-checker $9 \%$
Accepted 2020-10-21

(c) 2020 by Chetan L Rathod, Prakash Chauhan and Published by Siddharth Health Research and Social Welfare Society. This is an Open Access article licensed under a Creative Commons Attribution 4.0 International License https://creativecommons.org/licenses/by/4.0/ unported [CC BY 4.0]. 


\section{Introduction}

Fracture neck of femur is one of the commonly encountered injuries in orthopedics. It is more common in elderly individuals. In the 21st century, there is a significant challenge in the non-union of femur fracture in the field of orthopedics [1]. The fracture of the femur is very common in elderly individuals, however, due to an increase in the high incidence of trauma; there is an increase in the incidence of the fracture of the femur.

The young patient is more likely to present with associated injuries to other parts of the musculoskeletal system, as well as different organ systems. Unfortunately, the link between mechanism and risk of non-union has been difficult to establish, due to heterogeneity in definitions $[2,3]$.

The US Food and Drug Administration thereby defines a "fracture non-union" as a fracture which is at least 9 months old and does not show radiographic evidence of healing for 3 consecutive months. Previous literature has established, however, that healing metrics may be different depending on multiple patients and fracture characteristics, including fracture location.

Diagnosis of a non-union is most commonly established on standard radiography but often confirmed using advanced imaging modalities. Specific work-up as to the primary cause of nonunion should be individualized to the particular patient based on history and physical examination $[2,4]$.

Complications associated with fractured neck femur (non-union and avascular necrosis) make this injury all the more important. A femoral neck fracture is usually located intracapsular with synovial fluid bathing the fracture site interferes with the healing process. The femoral neck does not have a periosteal layer; hence the healing is entirely endosteal [5].

Pauwels showed that a higher shearing angle could lead to an unfavorable consolidating process. For this reason, a valgus osteotomy converts shearing into compression forces and increases the fracture healing potential [6]. Valgus intertrochanteric osteotomy alters the biomechanical environment of the fracture site and restores limb length $[7,8]$. Very few reports have dealt with the results of this procedure internally fixed with a dynamic hip screw and double angle barrel plate.
Hence, the prospective study was performed at the institution level for the evaluation of results of valgus osteotomy and fixation of the femur neck fracture in young patients.

\section{Materials and Methods}

The present study was done in the Department of Orthodontics, Mutthukumaran medical college Chennai, from May 2018 for two months. The present study was planned and the institutional ethical committee was informed about the study and the ethical clearance certificate was obtained before the start of the study. The study was done for one year.

A total of 32 patients with neglected and non-united femoral neck fractures were included in the study. All the patients were informed about the study and the procedure and written informed consent was signed by all the patients. The age range of the patients included in the study was 25 to 55 years. The mean age was found to be 41.8 years.

Inclusion criteria for the patients were as follows: patients with age less than 55 years, with fracture of neck of the femur for more than 3 weeks since injury and patients with fail primary fixation of the fracture of femur neck. The exclusion criteria were as follows: elderly patients with more than 55 years., the presence of avascular necrosis evident on radiographs or MRI, and significant resorption of the neck with proximal fragments less than $2.5 \mathrm{~cm}$.

A total of 32 patients were included in the study. There were 24 males and 8 females in the study. The average delay in the presentation after the fracture ranges from 5 weeks to 70 weeks. The reason for fracture was a road traffic accident in the fourteen patients, in twelve patients there was a fall in height the reason, in six patients the reason was of fall from ground. Before the fracture in all the patients, there was no history of any kind of difficulty in walking. All fractures were displaced (Garden grade 3 and 4) without any evidence of avascular necrosis ruled out by a preoperative plain radiograph or MRI scan.

Al the included patients had complained of pain and limited hip motion and they were unable to walk without support. Before osteotomy, the average neck-shaft angle was $101^{\circ}\left(80-120^{\circ}\right)$, with an average limb shortening of $2.3 \mathrm{~cm}(1.0-3.2 \mathrm{~cm})$. The greater trochanter was up riding in fourteen cases and needed skeletal traction before surgery. 
None of these had evidence of vascular necrosis on plain radiograph or MRI. The fractures were treated with a dynamic hip screw and double angle barrel plate. The patients had a minimum follow-up of 14 months and a maximum of 42 months.

After the surgery knee and ankle, physiotherapy was started the next day and the patients were mobilized with crutches non-weight-bearing from the third postoperative day. The patients were evaluated radiographically in an outpatient clinic at 8 weeks postoperatively and further at 6-week intervals until the union was achieved when full weight-bearing was started. Radiographic union was defined by the absence of a fracture line and the appearance of trabeculae across the fracture site.

\section{Results}

The present study was done to evaluate the results of valgus osteotomy and fixation of the femur neck fracture in young patients. A total of 32 patients were included in the study. The minimum month for the follow up was 14 months and the maximum up to 42 months. The Harris hip score was evaluated before the start of the surgery and after the end of the surgery. The average raise increased from 65 points to 90 points after the surgery.

In a total of 28 patients, excellent results were obtained, however, in 4 patients the poor result was due to cut - out of implants. None of the patients were lost on follow up, the fracture went on to achieve the satisfactory union after the minimum of 14 weeks follows up. The average preoperative neck-shaft angle of $101^{\circ}$ (range $80-120^{\circ}$ ) increased to $134^{\circ}$ (range $120-145^{\circ}$ ) after surgery. The average limb length discrepancy postoperatively was $2.3 \mathrm{~cm}$.

No patient had any serious immediate postoperative complications such as deep infection or deep vein thrombosis. No patient had coxa vara, defined as neck-shaft angle less than $120^{\circ}$, and osteotomy site united in all patients at an average time of 10.3 weeks (range 8-12weeks). All the patients with united fractures were able to sit cross-legged, squat, and do one-leg stance. Pain and limitation of motion improved remarkably so that the majority of the patients did not have to use crutches at 6 months after the operation.

Table-1: Distribution of patients according to results.

Results

Number

Percentage

\begin{tabular}{|l|l|l|}
\hline Excellent & 28 & 87.5 \\
\hline Poor & 4 & 12.5 \\
\hline Total & 32 & 100 \\
\hline
\end{tabular}

\section{Discussion}

Femoral neck fractures are associated with high rates of avascular necrosis and non-union. The complication rate is affected by the geometry of the fracture and any delay in treatment. Fractures that remain untreated after 3 to 6 weeks are defined as ununited and after $>90$ days as non-union. Fractures untreated after 3 weeks have less chance of bone union after internal fixation alone.

The two major advantages of valgus osteotomy are the preservation of bone stock and avoiding hip arthroplasty in young patients. In total hip arthroplasty is associated with high complication rates; infection and prosthesis loosening. 9 Though recent studies have shown increased survival rates in the young, head salvage remains the preferable treatment, especially in a patient population that routinely sits cross-legged or squats. Therefore, while THA is the option of choice in physiologically older patients, head salvage via a valgus osteotomy is preferred for the younger patient population [10].

Femoral neck fractures have been described in the past as the unsolved fracture. Fracture neck femur as such and neglected fracture neck femur in particular present a considerable challenge to the orthopedic surgeon as far as the union of the fracture is concerned [11].

Despite improved operative techniques, surgical technologies, hardware material, and theoretical understanding, osteonecrosis, and non-union continue to be the main complications of fracture of the femoral neck. Non-union rates of $10 \%$ to $59 \%$ have been reported and may be seen more frequently in young patients due to high-energy trauma [12].

Pauwel's study recognized that when the shearing force acting on fracture was transformed into compression forces the non-union of neck fracture of femoral bone would consolidate within the periods of few months.

Marti et al. reported $86 \%$ union in 50 patients at an average of 3.6 months, treated by this method alone. Twenty-two hips preoperatively had avascular necrosis, with three of these cases progressed to collapse, necessitating total hip replacement (THR) [13]. 
It is believed that valgus osteotomy acts as a biological stimulus for the healing of these fractures, promoting osteogenesis as a result of the conversion of shearing forces to compressive forces across the fracture site. The osteotomy is relatively easy to perform, cost-effective provides stability, and often is definitive one-time surgery.

In our present study, because of the delay in intervention and the young age of patients, Pauwels' osteotomy was performed as the head-salvaging procedure [14]. In the present study, because of the delay in intervention and the young age of patients, Pauwels' osteotomy was performed as the headsalvaging procedure. Union was achieved in $96.2 \%$ of our patients, which is quite good for any surgical intervention.

Among the united fractures, all were able to sit cross-legged, squat, and stand on the affected leg, which is needed in day-to-day life. This also is another advantage over the head-replacing procedure. Marti et al reported that collapse can occur 3-4 years later the following osteotomy. A follow-up period of 3 years in the present study was a limitation in this regard and longer follow-up is required for evaluation of collapse in the femoral head.

One disadvantage of repositioning valgus osteotomies is that valgisation of the proximal femur shortens the lever arm and alters the hip biomechanics, thus increasing contact pressure on the femoral head. This may increase the risk of osteoarthrosis and avascular necrosis.

\section{Conclusion}

From the study, it was concluded that valgus osteotomy and fixation with dynamic hip screw and $120^{\circ}$ double angle barrel plate has a high success rate in young patients with neglected and ununited intracapsular fracture neck of femur.

\section{What does the study add to the existing knowledge}

Valgus osteotomy at the subtrochanteric level and repositioning of the osteotomy is an effective treatment for un-united and neglected femoral neck fractures.

\section{Author's contribution}

Dr. Chetan L Rathod: Formulated the aims and
Objectives with study design and helped in data collection from the medical record department.

Dr. Prakash Chauhan: Manuscript preparation and data analysis.

\section{Reference}

01. Tsigaras H, MacDonald SJ. Femoral neck fractures- epidemiology and results and controversies in treatment. Controversies in Hip Surgery. 2003,2;121.

[Crossref]

02. Banaszek D, Spence D, O'Brien P, Lefaivre K. Principles of Valgus Intertrochanteric Osteotomy (VITO) after Femoral Neck Nonunion. Advances in orthopedics. 2018.

doi: $10.1155 / 2018 / 5214273$ [Crossref]

03. Moriarty TF, Harris LG, Mooney RA, Wenke JC, Riool M, Zaat SA, et al. Recommendations for design and conduct of preclinical in vivo studies of orthopedic device-related infection. Journal of Orthopaedic Research®. 2019;37(2)271-287.

doi: $10.1002 /$ jor.24230 [Crossref]

04. Van den Wyngaert T, Strobel K, Kampen W, Kuwert T, Van der Bruggen W, Mohan $\mathrm{H}$, et al. The EANM practice guidelines for bone scintigraphy. Eur J Nucl Med Mol Imaging. 2016;43(9)1723-1738.

doi: $10.1007 / \mathrm{s} 00259-016-3415-4 \quad$ [Crossref]

05. Bangarshettar AV. Intracapsular fracture neck of femur in elderly treated by hemiarthroplasty-a clinical study. RGUHS. 2006.

[Crossref]

06. Schwartsmann CR, Spinelli LdF, Yépez AK, Boschin LC, Silva MF. Femoral neck non-union treatment by valgus intertrochanteric osteotomy. Acta Ortop Bras. 2015;23(6)319322.

doi: $10.1590 / 1413-785220152306148750$ [Crossref]

07. Min BW, Bae KC, Kang CH, Song KS, Kim SY, Won YY. Valgus intertrochanteric osteotomy for non-union of femoral neck fracture. Injury. 2006;37(8)786-790.

doi: $\quad 10.1016 /$ j.injury.2006.02.045 [Crossref] 
08. Kulkarni SG, Kulkarni G, Babhulkar S, Kulkarni MG, Kulkarni RM. Accuracy of valgus osteotomy using dynamic hip screw. Injury. 2017;48(2)S2S7.

doi: $10.1016 / \mathrm{S} 0020-1383(17) 30486-2$ [Crossref]

09. Toms A, Davidson D, Masri B, Duncan C. The management of peri-prosthetic infection in total joint arthroplasty. J Bone Joint surg $\mathrm{Br}$. 2006;88(2)149-155.

doi: 10.1302/0301-620X.88B2.17058 [Crossref]

10. Varghese VD, Livingston $A$, Boopalan $P$, Jepegnanam TS. Valgus osteotomy for nonunion and neglected neck of femur fractures. World J Orthoped. 2016;7(5)301.

doi: 10.5312/wjo.v7.i5.301 [Crossref]

11. Büren C, Lögters $T$, Oezel L, Rommelfanger G, Scholz AO, Windolf J, et al. Effect of hyperbaric oxygen therapy (HBO) on implant-associated osteitis in a femur fracture model in mice. Plos one. $2018 ; 13(1)$ e0191594.

doi: 10.1371/journal.pone.0191594 [Crossref]
12. Singh S, Charles L, Maceachern CF, Changulani $M$. Complications of the surgical management of hip fractures. Orthopaed Trauma. 2016;30(2)137-144.

doi: $\quad 10.1016 /$ j.mporth.2016.03.008 [Crossref]

13. Marti RK, Schuller HM, Raaymakers E. Intertrochanteric osteotomy for non-union of the femoral neck. J Bone Joint Surg $\mathrm{Br}$. $1989 ; 71(5) 782-787$.

doi: 10.1302/0301-620X.71B5.2584247 [Crossref]

14. Elgeidi A, El-Negery A. Fibular strut graft for nonunited femoral neck fractures in children. J Child Orthop. 2017;11(1)28-35.

doi: 10.1302/1863-2548-11-160221 [Crossref] 